\title{
The management and outcome of hyponatraemia following transsphenoidal surgery: a retrospective observational study
}

\author{
Ziad Hussein $^{1,2}$ (D) Ploutarchos Tzoulis ${ }^{2,3} \cdot$ Hani J. Marcus ${ }^{4} \cdot$ Joan Grieve $^{4} \cdot$ Neil Dorward $^{4} \cdot$ Pierre Marc Bouloux $^{5}$. \\ Stephanie E. Baldeweg ${ }^{1,2}$
}

Received: 2 September 2021 / Accepted: 13 January 2022

(c) Crown 2022

\begin{abstract}
Purpose Hyponatraemia is a common complication following transsphenoidal surgery. However, there is sparse data on its optimal management and impact on clinical outcomes. The aim of this study was to evaluate the management and outcome of hyponatraemia following transsphenoidal surgery.

Methods A prospectively maintained database was searched over a 4-year period between January 2016 and December 2019, to identify all patients undergoing transsphenoidal surgery. A retrospective case-note review was performed to extract data on hyponatraemia management and outcome.

Results Hyponatraemia occurred in 162 patients $(162 / 670 ; 24.2 \%)$ with a median age of 56 years. Female gender and younger age were associated with hyponatraemia, with mean nadir sodium being $128.6 \mathrm{mmol} / \mathrm{L}$ on postoperative day 7 . Hyponatraemic patients had longer hospital stay than normonatraemic group with nadir sodium being inversely associated with length of stay $(p<0.001)$. In patients with serum sodium $\leq 132 \mathrm{mmol} / \mathrm{L}$, syndrome of inappropriate antidiuretic hormone secretion (SIADH) was the commonest cause $(80 / 111 ; 72 \%)$. Among 76 patients treated with fluid restriction as a monotherapy, 25 patients $(25 / 76 ; 32.9 \%)$ did not achieve a rise in sodium after 3 days of treatment. Readmission with hyponatraemia occurred in 11 cases $(11 / 162 ; 6.8 \%)$ at a median interval of 9 days after operation.

Conclusion Hyponatraemia is a relatively common occurrence following transsphenoidal surgery, is associated with longer hospital stay and risk of readmission and the effectiveness of fluid restriction is limited. These findings highlight the need for further studies to better identify and treat high-risk patients, including the use of arginine vasopressin receptor antagonists.
\end{abstract}

Keywords Hyponatraemia · Transsphenoidal surgery · Syndrome of Inappropriate ADH secretion · Pituitary adenoma

This article is part of the Topical Collection on Neurosurgery general

Ziad Hussein

ziad.hussein1@nhs.net

1 Department of Endocrinology, University College London Hospital, London, UK

2 Division of Medicine, University College London, London, UK

3 Department of Endocrinology, The Whittington Hospital, London, UK

4 Department of Neurosurgery, National Hospital for Neurology and Neurosurgery, London, UK

5 Centre for Neuroendocrinology, Royal Free Campus, University College Medical School, University College London, London, UK

\section{Introduction}

Postoperative hyponatraemia, defined as serum sodium value less than $135 \mathrm{mmol} / \mathrm{L}$ within 30 days of surgery, is a frequent complication following transsphenoidal surgery for pituitary adenoma, with a reported incidence of $16-23 \%[1,2,19,33$, 36]. The most common aetiology is syndrome of inappropriate antidiuretic hormone secretion (SIADH) as a consequence of surgical manipulation of the neurohypophysis and hypothalamus[2, 14, 15]. Other causes include cerebral salt wasting syndrome (CSWS), hypocortisolism due to adrenocorticotropic hormone (ACTH) deficiency, severe hypothyroidism, overzealous desmopressin (DDAVP) administration and hypotonic fluid infusion[2, 13]. The optimal therapeutic strategy for postoperative hyponatraemia differs according to its cause. Fluid restriction remains the mainstay of treatment 
in SIADH, fluid and sodium replenishment are the treatment of choice in CSWS, whereas glucocorticoid and thyroxine replacement are required for adrenal and thyroid deficiency, respectively.

Despite recent initiatives in the USA and the UK[4, 24], hyponatraemia remains the leading cause of unplanned hospital readmissions within 30 days of transsphenoidal surgery for pituitary tumours $[3,4,6]$. To this end, the aim of this study was to evaluate the management and outcome of hyponatraemia following transsphenoidal surgery.

\section{Methods}

\section{Study design and population}

A retrospective case control study design was adopted, and the study was registered and approved by the local Clinical Governance Committee. The Strengthening the Reporting of Observational Studies in Epidemiology (STROBE) Statement was used in the preparation of this section of the manuscript[9].

A prospectively maintained database was searched over a 4-year period between 1st January 2016 and 31st December 2019, to identify all patients undergoing transsphenoidal surgery that were found to have serum sodium less than $135 \mathrm{mmol} / \mathrm{L}$ during their hospitalisation. The study was conducted at the National Hospital for Neurology and Neurosurgery, which performs the highest volume of pituitary operations in the UK. Operations were performed by three experienced neurosurgeons using either an operating microscope (JG) or endoscope (HJM and NLD).

\section{Data collection}

Demographic, clinical, laboratory and radiological data were obtained from each patient's medical records. Pituitary adenomas were classified according to their size and endocrine activity. The pre-operative adenoma size was determined using magnetic resonance imaging (MRI), with pituitary microadenoma being defined as an adenoma with a diameter less than $1 \mathrm{~cm}$ and pituitary macroadenoma as an adenoma with a diameter equal or more than $1 \mathrm{~cm}$. The diagnosis of functioning and non-functioning pituitary adenomas was based on standard endocrine assessment and histological analysis of the resected tumours. Histological diagnosis of other sellar and parasellar lesions was also recorded.

All patients underwent measurement of anterior pituitary hormones prior to surgery and on the second post-operative day. Patients noted to have secondary adrenal insufficiency and/or hypothyroidism were treated with replacement therapy. Hypocortisolism was defined as early morning serum cortisol less than $350 \mathrm{nmol} / \mathrm{L}$, and secondary hypothyroidism was defined as free T4 level less than $12 \mathrm{pmol} / \mathrm{L}$ (reference range $12-22 \mathrm{pmol} / \mathrm{L}$ ).

Serum sodium was recorded at baseline preoperatively and daily during the first week postoperatively. Hyponatraemia in this study was classified into mild (serum sodium level between 130 and $134 \mathrm{mmol} / \mathrm{L}$ ), moderate (serum sodium level between 125 and $129 \mathrm{mmol} / \mathrm{L}$ ) and severe hyponatraemia (serum sodium level less than $125 \mathrm{mmol} / \mathrm{L}$ ) [35]. Nadir sodium is the lowest sodium level measured at any point within 30 days following transsphenoidal surgery. In our institution, serum sodium of $132 \mathrm{mmol} / \mathrm{L}$ is considered clinically meaningful and prompts management. Therefore, data on the management and outcome of hyponatraemia were extracted for those who developed serum sodium $\leq 132 \mathrm{mmol} / \mathrm{L}$ following surgery. Renal function, serum osmolality, urine osmolality and sodium, serum cortisol and thyroid function were also recorded. The diagnosis of SIADH was made in those who met the diagnostic criteria of clinical euvolaemia, measured serum osmolality $<275 \mathrm{mOsm} / \mathrm{kg}$, urine osmolality $>100 \mathrm{mOsm} / \mathrm{kg}$ and urine sodium $>30 \mathrm{mmol} / \mathrm{L}$, as well as normal adrenocortical and thyroid function, without recent administration of diuretics[35]. Data on treatment and serum sodium level post treatment initiation were recorded. Data on short-term outcomes, including intensive care unit admission and length of hospital stay, as well as on readmission rate were collected.

\section{Statistical analysis}

Basic data were evaluated using descriptive statistics. Mean and standard deviation (SD) were used to describe continuous variables. Median and interquartile range (IQR) were used to describe data not normally distributed. Chi square test was used to compare categorical variables including the trend in postoperative sodium level. Linear regression analysis was used to evaluate the relationship of nadir sodium with patient's age, gender and length of stay. Statistical significance was defined as $p$ value $<0.05$. Statistical analysis was performed using GRAPHPAD PRISM 8 software.

\section{Results}

\section{Baseline characteristics and risk factors for hyponatraemia in all patients with serum sodium level $<135 \mathrm{mmol} / \mathrm{L}$}

Among 670 patients who underwent transsphenoidal surgery over 4 years, 162 patients $(162 / 670 ; 24.2 \%)$ developed hyponatraemia (serum sodium $<135 \mathrm{mmol} / \mathrm{L}$ ) 
postoperatively. Mild hyponatraemia occurred in 90 patients $(90 / 670 ; 13.4 \%), 38$ patients had moderate hyponatraemia $(38 / 670 ; 5.7 \%)$ and severe hyponatraemia was recorded in 34 patients (34/670; 5.1\%).

Patients' characteristics, tumour histology and surgical approach are shown in Table 1. The median age for hyponatraemic patients was 56 years (IQR 44-68). Younger age was associated with hyponatraemia $(p=0.043)$. On average, the value of nadir sodium increased by $0.05 \mathrm{mmol} / \mathrm{L}$ for each year increase of age $\left(F(1,159)=4.18, p=0.043, R^{2}=\right.$ 0.03) (Fig. 1)

There was no difference in the incidence of hyponatraemia observed between males and females $(p=0.4)$. However, female gender was significantly associated with lower nadir level (mean sodium $=124.8 \mathrm{mmol} / \mathrm{L}$ ) than with male gender (mean sodium $=133 \mathrm{mmol} / \mathrm{L})(p<0.001)$.

There was no significant difference in the frequency of hyponatraemia between patients with microadenoma and those with macroadenoma ( $p=0.7)$ (Table 2). The frequency of hyponatraemia was similar in patients with pituitary macroadenoma with and without optic nerve $(p=0.8)$. In addition, there was no difference in the frequency of hyponatraemia between patients with functioning and non-functioning adenomas $(p=0.5)$. Although patients with craniopharyngioma developed hyponatraemia at a higher rate than those

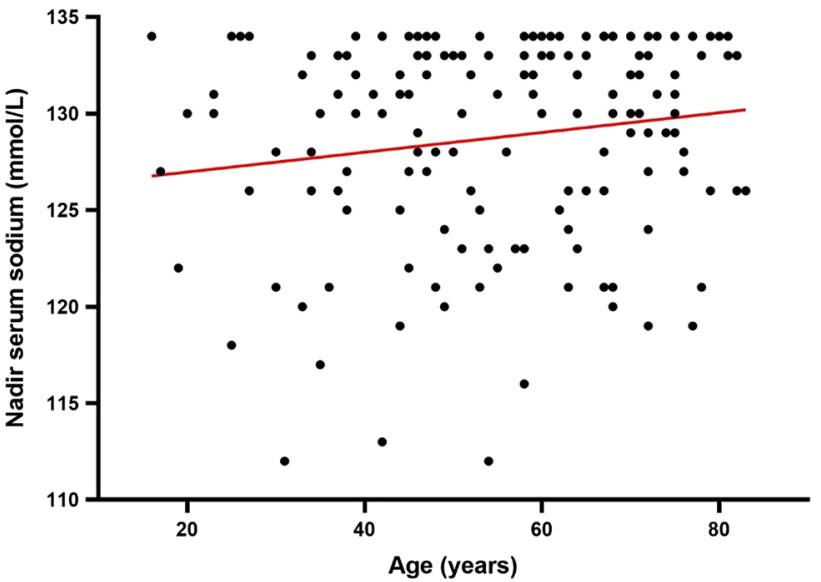

Fig. 1 Linear regression analysis of age and nadir serum sodium. $\mathrm{X}$ axis represents patients' age in years, and $\mathrm{Y}$ axis represents nadir serum sodium $(\mathrm{mmol} / \mathrm{L})$. Individual sodium levels plotted as dark circles

with pituitary adenoma, this was not statistically significant (39.2\% versus $22.3 \%$; $p=0.06$ ). With respect to the neurosurgical technique, the occurrence rate of hyponatraemia was similar between microscopic and endoscopic transsphenoidal surgeries $(p=0.4)$.

Table 1 The incidence of hyponatraemia among all patients treated with transsphenoidal surgery. Patients' characteristics, surgical technique and tumour pathology are represented in numbers and percentages

\begin{tabular}{|c|c|c|c|c|}
\hline & $\begin{array}{l}\text { Hyponatraemia } \\
(<135 \mathrm{mmol} / \mathrm{L})\end{array}$ & $\begin{array}{l}\text { Normonatraemia } \\
(135-145 \mathrm{mmol} / \mathrm{L})\end{array}$ & Total & $p$ value \\
\hline \multicolumn{5}{|l|}{ Patient's gender } \\
\hline Male & $77(22.9 \%)$ & 259 & 336 & $p=0.4$ \\
\hline Female & $85(25.4 \%)$ & 249 & 334 & \\
\hline \multicolumn{5}{|l|}{ Surgical technique } \\
\hline Microscopic surgery & $107(25.2 \%)$ & 316 & 423 & $p=0.4$ \\
\hline Endoscopic surgery & $55(22.2 \%)$ & 192 & 247 & \\
\hline \multicolumn{5}{|l|}{ Tumour pathology } \\
\hline Pituitary adenoma & $122(22.3 \%)$ & 424 & 546 & \\
\hline Craniopharyngioma & $11(39.2 \%)$ & 17 & 28 & \\
\hline Rathke's cleft cyst & $6(23.1 \%)$ & 20 & 26 & \\
\hline Meningioma & $6(23.1 \%)$ & 20 & 26 & \\
\hline Pituitary metastasis & $3(30 \%)$ & 7 & 10 & \\
\hline Pituitary inflammation & $1(11.1 \%)$ & 8 & 9 & \\
\hline Epidermoid cyst & $2(50 \%)$ & 2 & 4 & \\
\hline Pituicytoma & $1(33.3 \%)$ & 2 & 3 & \\
\hline $\begin{array}{l}\text { Rare pathologies (der- } \\
\text { moid cyst, glioneuronal } \\
\text { tumour, germinoma, } \\
\text { infection, chordoma, } \\
\text { cavernoma, glioma, } \\
\text { unknown) }\end{array}$ & $10(55 \%)$ & 8 & 18 & \\
\hline
\end{tabular}


Table 2 The occurrence of hyponatraemia in patients with pituitary adenoma. Patients are represented with numbers and percentages

\begin{tabular}{|c|c|c|c|c|}
\hline & $\begin{array}{l}\text { Hyponatraemia } \\
(<135 \mathrm{mmol} / \mathrm{L})\end{array}$ & $\begin{array}{l}\text { Normonatrae- } \\
\text { mia } \\
(135- \\
145 \mathrm{mmol} / \mathrm{L})\end{array}$ & Total & $p$ value \\
\hline Pituitary adenoma (total) & $122(22.3 \%)$ & 424 & 546 & \\
\hline \multicolumn{5}{|l|}{ Adenoma size on radiology } \\
\hline Microadenoma & $15(20.0 \%)$ & 60 & 75 & \multirow[t]{2}{*}{$p=0.7$} \\
\hline Macroadenoma (total) & $107(22.7 \%)$ & 364 & 471 & \\
\hline Macroadenoma without optic nerve compression & $28(21.5 \%)$ & 102 & 130 & \multirow[t]{2}{*}{$p=0.8$} \\
\hline Macroadenoma with optic nerve compression & $79(23.1 \%)$ & 262 & 341 & \\
\hline \multicolumn{5}{|l|}{ Pituitary adenoma endocrine hyperfunction } \\
\hline FPA & $35(25.7 \%)$ & 136 & 171 & \multirow[t]{2}{*}{$p=0.5$} \\
\hline NFPA & $87(23.2 \%)$ & 288 & 375 & \\
\hline \multicolumn{5}{|l|}{ Pituitary adenoma pathology } \\
\hline Gonadotropin expressing (non-secreting) adenoma & $64(24.3 \%)$ & 199 & 263 & \\
\hline Acromegaly & $14(16.6 \%)$ & 70 & 84 & \\
\hline Cushing's disease & $15(22.0 \%)$ & 53 & 68 & \\
\hline Null cell & $11(22.4 \%)$ & 38 & 49 & \\
\hline Silent corticotroph & $4(12.9 \%)$ & 27 & 31 & \\
\hline Functioning prolactinoma & $6(31.5 \%)$ & 13 & 19 & \\
\hline Plurihormonal adenoma & $4(21.0 \%)$ & 15 & 19 & \\
\hline Non-functioning TSH expressing adenoma & $3(42.8 \%)$ & 4 & 7 & \\
\hline Non-functioning GH expressing adenoma & $0(0 \%)$ & 3 & 3 & \\
\hline Non-functioning prolactin expressing adenoma & $1(33 \%)$ & 2 & 3 & \\
\hline
\end{tabular}

FPA functioning pituitary adenoma, $G H$ growth hormone, NFPA non-functioning pituitary adenoma, TSH thyrotropin stimulating hormone

\section{Incidence, time course and severity of hyponatraemia in all patients with serum sodium $<135 \mathrm{mmol} / \mathrm{L}$}

Prior to surgery, ten patients $(10 / 156 ; 6.4 \%)$ had pre-existing hyponatraemia with a level of $132.2( \pm 3.5) \mathrm{mmol} / \mathrm{L}$. The median time for serum sodium to decrease below $135 \mathrm{mmol} / \mathrm{L}$ was 4 days (IQR 1-6) after tumour resection. The mean $( \pm \mathrm{SD})$ nadir sodium level for all patients was $128.6( \pm 5.2) \mathrm{mmol} / \mathrm{L}$, and the median timepoint to exhibit nadir sodium was postoperative day 7 (IQR 2-8). Nadir sodium according to hyponatraemia severity is shown in Table 3. Nadir sodium varied according to the aetiology. In SIADH, nadir level was $125.1( \pm 5) \mathrm{mmol} / \mathrm{L}$ with a median time of onset of 8 days (IQR 6-9 days). In patients with adrenal insufficiency, lowest sodium concentration was $130( \pm 2.4) \mathrm{mmol} / \mathrm{L}$, occurring after a median time period of 1 day (IQR 1-5). In patients with DDAVP overreplacement, nadir sodium was 127 $( \pm 4.4) \mathrm{mmol} / \mathrm{L}$ with a median duration of 7 days (IQR 3-9) postoperatively.

We examined the trend of hyponatraemia according to the severity during the first postoperative week. Mild hyponatraemia was more common in the early postoperative period, mostly on day $1(p=0.0001)$, while severe hyponatraemia started from day two and evolved in a

Table 3 The timing and impact of hyponatraemia according to severity on regaining normal sodium level and inpatient hospital stay

\begin{tabular}{|c|c|c|c|}
\hline & Mild hyponatraemia & Moderate hyponatraemia & Severe hyponatraemia \\
\hline Mean nadir $\mathrm{Na}(\mathrm{SD})$ & $132.5( \pm 1.4)$ & $127( \pm 1.2)$ & $120( \pm 3.3)$ \\
\hline Median time to exhibit nadir Na post TSS (IQR) & 3.5 days $(1-8)$ & 7 days $(2-8)$ & 8 days (7-9) \\
\hline $\begin{array}{l}\text { Median time to achieve normal Na post hyponatraemia } \\
\text { therapy (IQR) }\end{array}$ & 2 days $(1-3)$ & 4 days $(2-6)$ & 6 days (4-9) \\
\hline Median hospital stay (IQR) & 7 days $(5-10)$ & 12 days $(7-16)$ & 11 days $(7-16)$ \\
\hline
\end{tabular}

$I Q R$ interquartile range, $S D$ standard deviation, $\mathrm{Na}$ sodium 
delayed pattern most commonly on day $7(p=0.0001)$ (Supplementary Figure). Mean serum sodium during the first 7 days following transsphenoidal surgery according to hyponatraemia severity is shown in Fig. 2.

\section{Investigations and aetiology for patients with serum sodium $\leq 132 \mathrm{mmol} / \mathrm{L}$}

One hundred and eleven patients had serum sodium levels of $132 \mathrm{mmol} / \mathrm{L}$ and below. The commonest cause was SIADH $(80 / 111 ; 72 \%)$, followed by adrenal insufficiency $(9 / 111 ; 8.1 \%)$, overzealous treatment of cranial diabetes insipidus with DDAVP $(6 / 111 ; 5.4 \%)$ and hypotonic hyponatraemia due to hypotonic fluid administration $(3 / 111 ; 2.7 \%)$. There were no documented cases of CSWS. No clear diagnosis was documented in 13 patients $(13 / 111 ; 11.7 \%)$. Table 4 demonstrates biochemical assessment results for patients with SIADH.

All patients had early morning cortisol checked $48 \mathrm{~h}$ postoperatively. In patients with a new onset of secondary adrenal insufficiency, mean morning cortisol was 138.7 $( \pm 84) \mathrm{nmol} / \mathrm{L}$. Thyroid status was assessed in all patients pre-operatively and postoperatively with mean free $\mathrm{T} 4$ level of $18( \pm 5) \mathrm{pmol} / \mathrm{L}$ (reference range 12-22 pmol/L). Notably, 11 patients had low free T4 level prior to surgery which was treated appropriately with levothyroxine replacement.

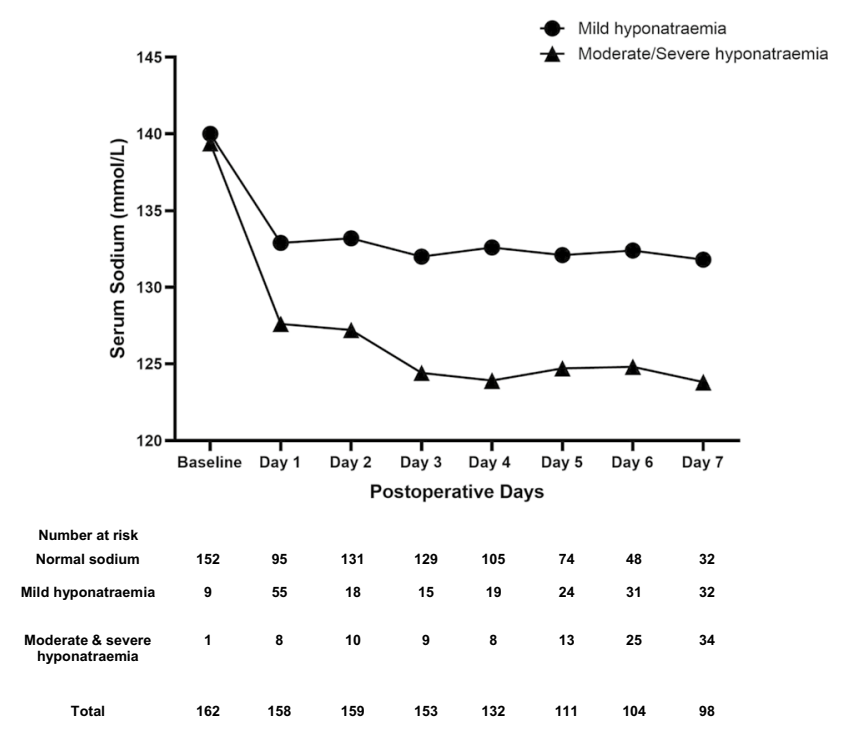

Fig. 2 Mean serum sodium during the first 7 days following transsphenoidal surgery according to hyponatraemia severity. Sodium levels in mild hyponatraemia are expressed in black circles, in moderate and severe hyponatraemia in black triangles
Table 4 The diagnostic work-up of hyponatraemia for patients with syndrome of inappropriate antidiuretic hormone secretion. Results are expressed in mean levels and standard deviation (SD)

\begin{tabular}{ll}
\hline & Mean level $( \pm \mathrm{SD})$ \\
\hline Nadir serum sodium $(135-145 \mathrm{mmol} / \mathrm{L})$ & $125.1( \pm 5)$ \\
Urea $(1.7-8.3 \mathrm{mmol} / \mathrm{L})$ & $4.6( \pm 1.7)$ \\
Serum creatinine $(66-112 \mu \mathrm{mol} / \mathrm{L})$ & $63( \pm 21)$ \\
Serum osmolality $(285-295 \mathrm{mOsm} / \mathrm{kg})$ & $265( \pm 13)$ \\
Urinary osmolality $(300-900 \mathrm{mOsm} / \mathrm{kg})$ & $508( \pm 223)$ \\
Urinary sodium $(\mathrm{mOsm} / \mathrm{kg})$ & $80( \pm 50)$ \\
\hline
\end{tabular}

\section{Treatment of hyponatraemia in patients with serum sodium $\leq 132 \mathrm{mmol} / \mathrm{L}$}

Fluid restriction was imposed on 83 patients with serum sodium $\leq 132 \mathrm{mmol} / \mathrm{L}$; this included 80 patients with SIADH, 3 patients with fluid overload.

For patients with SIADH, $72(72 / 80 ; 87.8 \%)$ had fluid restriction as a monotherapy. Of those, 60 patients had fluid restriction between 500 and $1000 \mathrm{~mL}$ daily, and 12 patients reduced fluid intake to $1500 \mathrm{~mL}$ daily.

Fluid restriction as a monotherapy achieved a mean increase in serum sodium of $3.3 \mathrm{mmol} / \mathrm{L}$ over a 3 -day period. Notably, 23 patients $(23 / 72 ; 31.9 \%)$ did not achieve any increase in sodium levels during the first 3 days of fluid restriction, four patients $(4 / 72 ; 5.5 \%)$ had a mean sodium increase of $1-2 \mathrm{mmol} / \mathrm{L}, 8$ patients $(8 / 72 ; 11.1 \%)$ had 3-4 mmol/L sodium increase and 37 patients (37/72; $51.3 \%$ ) had sodium increment of $\geq 5 \mathrm{mmol} / \mathrm{L}$ during the first 3 days of fluid restriction. The median time to achieve an increase in serum sodium of $\geq 5 \mathrm{mmol} / \mathrm{L}$ was 3 days (IQR 2-6 days) and to achieve normal sodium concentration was

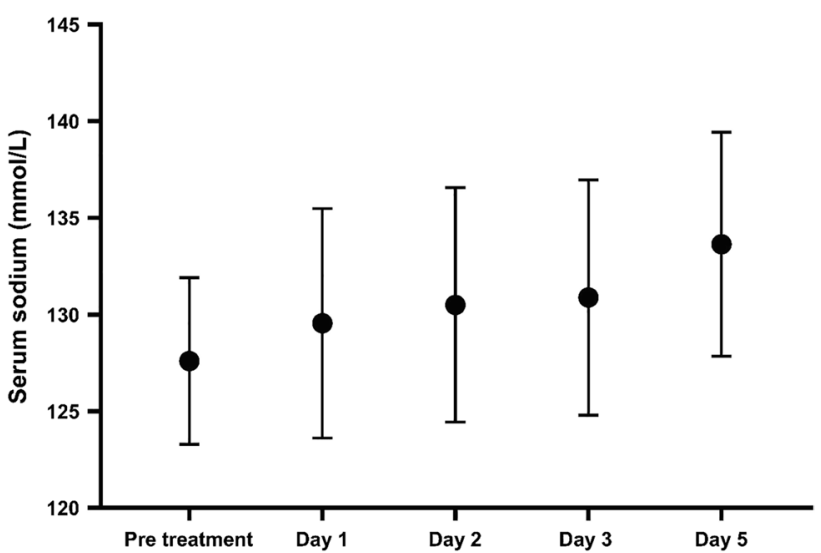

Fig. 3 Serum sodium concentration after starting fluid restriction. Sodium levels are expressed as mean and standard deviation. The black circles represent mean sodium levels for those treated with fluid restriction 
4 days (IQR 2-6). Figure 3 demonstrates sodium levels at baseline and after starting fluid restriction in those received fluid restriction only.

Second-line treatment for SIADH was administered in a total of 8 patients; with hypertonic saline $1.8 \%$ being used in 5 patients $(5 / 84 ; 5.9 \%)$, hypertonic saline $2.7 \%$ in 1 patient $(1 / 84 ; 1.1 \%)$, sodium chloride tablets in 1 patient $(1 / 84$; $1.1 \%)$ and tolvaptan at a dose of $7.5 \mathrm{mg}$ in one patient (1/84; $1.1 \%)$. The patient who was treated with $2.7 \%$ hypertonic saline and the second one who received tolvaptan developed overly rapid correction of sodium by more than $10 \mathrm{mmol} / \mathrm{L}$ over the first $24 \mathrm{~h}$.

Patients diagnosed with new onset of secondary adrenal insufficiency (number $=9$ ) received glucocorticoid replacement and achieved a mean sodium increase of $8 \mathrm{mmol} / \mathrm{L}$ in the first 3 days post therapy. Patients with DDAVP over replacement (number $=6$ ) were treated by dose down titration, leading to a mean sodium increase of $8 \mathrm{mmol} / \mathrm{L}$ during the first 3 days of therapy. No patients were treated with urea or demeclocycline.

\section{Outcome for all patients with hyponatraemia $<135 \mathrm{mmol} / \mathrm{L}$}

The mean serum sodium level on discharge for the full cohort was $137.3( \pm 4.2) \mathrm{mmol} / \mathrm{L}$. For the full cohort (number $=162$ ), hyponatraemia was corrected in 4 days (IQR 2-6 days), and the length of hospital admission was longer for patients with hyponatraemia (median $=8$ days [IQR 5-14]) than the patients who remained normonatraemic throughout hospitalisation (median $=5$ days [IQR 4-7]) $(p<0.001)$. Lower nadir sodium was significantly associated with longer inpatient stay. On average, $1 \mathrm{mmol} / \mathrm{L}$ reduction in sodium concentration resulted in an increase of inpatient stay by 0.39 days $\left(F(1,154)=14.39, p<0.001, R^{2}=0.09\right)$ (Fig. 4).

Seven patients out of $162(7 / 162 ; 4.3 \%)$ were admitted to the intensive care unit with a median stay of 3 days (IQR 2-4). One patient had a seizure secondary to severe hyponatraemia. No patients developed permanent neurological morbidities, and there was no associated mortality.

Among 162 patients who developed hyponatraemia, a subset of eleven patients $(11 / 162 ; 6.7 \%)$ had normal sodium levels during initial hospitalisation; however, they were readmitted post discharge with hyponatraemia during the first 30 days of surgery. Those patients were discharged after a median length of initial hospital stay of 4 days (IQR $4-6)$. Six patients $(6 / 11 ; 54.5 \%)$ were men and five $(5 / 11$; $45.5 \%)$. The median time of readmission from surgery was 9 days (IQR 7-10). All patients had severe hyponatraemia due to SIADH with a mean sodium level of $120.1( \pm 4.4)$ $\mathrm{mmol} / \mathrm{L}$. Among the 11 patients who were readmitted, 8 patients $(8 / 11 ; 72.7 \%)$ were treated with fluid restriction,

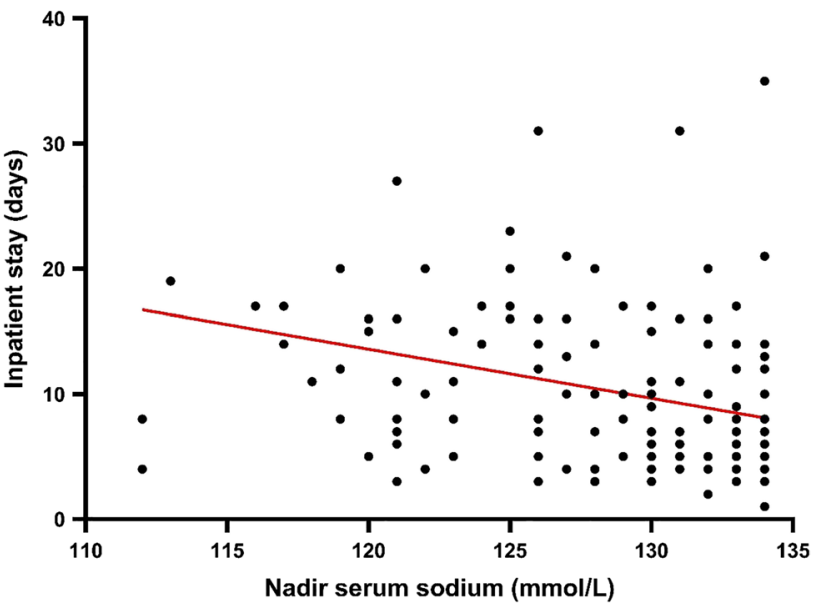

Fig. 4 The relationship between mean nadir serum sodium $(\mathrm{mmol} / \mathrm{L})$ and in-hospital length of stay in days. In-hospital stay represented in days are expressed as black circles

two $(2 / 11 ; 18.1 \%)$ were treated with both fluid restriction and $1.8 \%$ hypertonic saline in the intensive care unit and one $(1 / 11 ; 9 \%)$ patient was treated with a combination of fluid restriction and $2.7 \%$ hypertonic saline. The median duration to regain normal sodium levels was 4 days (IQR 3-6), and median duration to hospital discharge was 5.5 days (IQR $3-10)$.

\section{Discussion}

\section{Principal findings}

This is a real-world study of 670 patients who underwent transsphenoidal surgery in the largest pituitary neurosurgical centre in the UK. We report the following principal findings: (1) the prevalence of post-operative hyponatraemia was $24.2 \%$; (2) female gender and young age were associated with hyponatraemia; (3) tumour size, optic nerve compression, functional status of pituitary adenomas and surgical technique were not predictors for the development of postoperative hyponatraemia; (4) hyponatraemia was mainly due to SIADH, with day 4 being the median time of onset of hyponatraemia and nadir sodium being reported around seven days postoperatively; (5) fluid restriction was used as the treatment strategy in the majority of SIADH patients and was often ineffective in correcting hyponatraemia, leading to prolonged hospitalisation; 6) hyponatraemia was not associated with any long-term neurological sequalae or mortality.

\section{Comparison with other studies}

This study reports a prevalence of post-operative hyponatraemia at $24.2 \%$, in agreement with $16-23 \%$ 
frequency reported in other studies[2, 22, 29, 43, 44]. This series identified two factors associated with postoperative hyponatraemia, female gender and younger age. According to Barber and Zada et al.[2, 45], female gender, but not age, was a risk factor for developing hyponatraemia, while Rajaratnam et al.[31] documented that males had a higher risk of hyponatraemia. The novel finding in this cohort is that the incidence of hyponatraemia increased with younger age. This contrasts with the findings of Hussain et al.[18] and Tomita et al.[36] who reported a link of older age with hyponatraemia, while other reports have not found an association between age and hyponatraemia[2, $19,45]$. In this cohort, tumour size, optic nerve compression, functional status of pituitary adenomas and surgical technique (microscopic versus endoscopic) were not shown to increase the risk of developing hyponatraemia in contrast to other studies[16, 21, 24].

In line with other studies, we confirmed SIADH as the leading cause of hyponatraemia following transsphenoidal surgery. The exact pathogenesis of hyponatraemia following pituitary surgery is not fully understood. Disturbance of fluid balance and, subsequently, of serum sodium because of dysfunctional osmoregulation usually occurs several days after surgical resection, resulting in antidiuresis and hypoosmotic hyponatraemia [26, 28, 39]. Dysregulated secretion of arginine vasopressin (AVP) from the damaged posterior pituitary terminals and magnocellular neurones may result in SIADH and subsequent water imbalance [7, 32]. A prospective study of 92 patients who underwent transsphenoidal pituitary surgery by Olson et al.[28] demonstrated aberrant AVP production with impaired water excretion after water load test in all patients with hyponatraemia and in two-thirds of those with normal sodium. Besides impaired aquaresis, other factors, such as low dietary sodium intake, excessive fluid intake and natriuresis, contributed to the development of hyponatraemia. Hyponatraemia after pituitary surgery has a complex pathophysiological basis and is attributed to multiple factors, including extent of surgical manipulation, damage to the neurohypophysis and hypothalamus, the degree of thirst, fluid volume and dietary sodium intake in the postoperative period. CSWS is a rare but a proposed cause of postoperative hyponatraemia following transsphenoidal surgery. This condition is characterised by excessive renal sodium wasting and circulatory volume depletion in the setting of normal renal and hypothalamic-pituitary-adrenal functions[27]. Despite being first described many decades ago by Peters et al.[30], the causative mechanism and optimal management is still debated. Although it can be challenging in clinical practice, it is considered critically vital to distinguish between SIADH and CSWS, as SIADH is routinely managed with fluid restriction, whereas the main therapy for CSWS is fluid and sodium replenishment. Interestingly, we did not report a single case of CSWS. Our data contradicted the finding by Barber et al.[2] that $24 \%$ of hyponatraemic patients post-pituitary surgery had CSWS.

Other, less frequent, causes of hyponatraemia are hypocortisolism, severe hypothyroidism, DDAVP overreplacement and hypotonic fluid administration.

Fluid restriction is the standard first line therapy for the management of SIADH but with controversial efficacy. It is known for its limited effectiveness in treating SIADH, irrespective of its aetiology[2, 12, 41]. In clinical practice, the volume of fluid restriction is generally based on physician's experience and usually tailored to each individual patient. We recommend using urine/plasma electrolyte ratio formula (urine sodium + urine potassium)/(plasma sodium) as a useful predictive formula to guide water restriction [10]; for example for a ratio of $<0.5$ we suggest water limitation up to $1 \mathrm{~L} /$ day whereas for a ratio between 0.5 and 1 we suggest restricting fluid to less than $500 \mathrm{~mL} /$ day. Others have recommended limiting daily fluid intake to $500 \mathrm{~mL}$ below 24-h urine output and use urine osmolality of $>500 \mathrm{mOsm} /$ $\mathrm{kg}$ water or urine/plasma electrolyte ratio $>1$ as a cutoff to employ pharmacological therapy as a first line treatment instead of fluid restriction [23][23]. Some of the well-recognised issues with fluid restriction are poor tolerance, patient adherence and the difficulty of implementing in clinical practice. We consider patient education by a trained health professional paramount to achieve a successful outcome and encourage patients to do self-fluid balance recording as one of the ways to increase treatment awareness and perception. This series showed that one-third of patients did not respond to fluid restriction within the first 3 days of treatment, while responders required a median time period of 4 days to restore normal sodium. These management outcomes are in contrast to other studies by Burke et al. and Winogard et al. [5, 42], who advocate the implementation of $1000-\mathrm{mL}$ fluid restriction following discharge for all patients during the first week following transsphenoidal surgery, irrespective of whether they have hyponatraemia. They reported successful outcomes of higher sodium levels and less hospital readmission in the interventional group than those who had no restriction. We, however, only managed patients with documented hyponatraemia with fluid restriction during inpatient stay; we think this approach provides more robust data about the efficacy of fluid restriction in treating SIADH as applying treatment in the outpatient setting may be liable to missing some data, particularly with respect to daily serum sodium response. Finally, the mean sodium increase of $3.3 \mathrm{mmol} / \mathrm{L}$ after 3 -day fluid restriction reported in our study is almost identical to the increase documented in the first ever, and only so far, randomised controlled trial of fluid restriction[11].

Some authors consider commencing tolvaptan if there is no response or suboptimal increase in serum sodium after 24-48 h of fluid restriction[17, 23, 37]. Tolvaptan is 
a vasopressin receptor antagonist and has been used for the treatment of euvolemic hyponatremia since 2008 with much higher effectiveness in sodium correction than fluid restriction[23, 34, 41]. However, concerns have been raised about the risk of overly rapid sodium correction and subsequent deleterious outcome[25, 38, 40, 41]. A recent study by Kleindienst et al.[22], the only one comparing tolvaptan versus fluid restriction in the treatment of SIADH following pituitary surgery, reported that tolvaptan at a small dose $(7.5 \mathrm{mg})$ was more effective than fluid restriction in the treatment of SIADH but resulted in overly rapid correction of serum sodium in a significant percentage of cases, without shortening the duration of hospitalisation. We recommend using tolvaptan under close guidance of Endocrinologists and Nephrologists with regular monitoring of sodium concentration every $4-6 \mathrm{~h}$ following its initiation. If serum sodium incremented by more than $6 \mathrm{mmol} / \mathrm{L}$ at $6 \mathrm{~h}$ or $10 \mathrm{mmol} / \mathrm{L}$ in $24 \mathrm{~h}$, then hypotonic $5 \%$ dextrose solution should be administered at a volume matching the urine output to halt further sodium overcorrection[37]. Hypertonic saline $3 \%$ is another treatment modality for hypotonic hyponatraemia but is limited to patients with adverse neurological symptoms such as confusion, seizures and dropping Glasgow Coma Scale secondary to hyponatraemia[35] [35]. We recommend intravenous infusion of $150 \mathrm{~mL} \mathrm{3 \%}$ solution over $20 \mathrm{~min}$. Treatment can be repeated twice to achieve $5 \mathrm{mmol} / \mathrm{L}$ increment in sodium concentration with close monitoring required ideally in the intensive care unit. Other treatment modalities, such as urea, demeclocycline and lithium, are not recommended due to the lack of clear evidence, side-effect profile and limited efficacy[35].

We demonstrated a significant association between hyponatraemia and duration of hospital stay with an increase of 4 days in the duration of hospital stay of hyponatraemic patients compared to those with normal sodium. In addition, the severity of biochemical hyponatraemia was related to the length of hospital stay. Tomita et al.[36] also reported longer hospital stay in those who underwent endoscopic surgery for pituitary adenoma only. We reported this outcome for all sellar and parasellar pathologies.

Unplanned hospital admissions following transsphenoidal surgery are associated with significant clinical and financial implications[20]. Hyponatraemia has been reported as the commonest cause of unplanned readmission following transsphenoidal surgery for pituitary tumours $[3,44]$. There is sparse data about the aetiology and predictive factors for rehospitalisation with hyponatraemia[3]. A potential strategy to decrease readmissions due to hyponatraemia would include routine assessment of serum sodium levels in all patients 5-7 days after operation, allowing early identification of hyponatraemia and prompt initiation of fluid restriction on outpatient basis[24]. An alternative pathway to lower readmission rate is to limit fluid intake in all patients post discharge $[8,42]$. However, to date there is no general consensus in respect to the best strategy to identify patients at risk and manage delayed hyponatraemia post discharge. This highlights the need to educate patients about the risk of developing delayed hyponatraemia following transsphenoidal surgery and increase patient's awareness of the clinical symptoms caused by severe hyponatraemia in this setting as well as the importance of measuring serum sodium on days 7-9 after surgery.

\section{Strengths and weaknesses}

The main strength of this study is that it assessed the incidence, management and clinical outcome of hyponatraemia following transsphenoidal surgery in a large cohort of patients. In addition, we reported a detailed impact of different degrees of hyponatraemia on several patient specific clinical outcomes as well as the effectiveness of treatment in those patients which many other studies did not analyse.

This study was based on a retrospective review of medical records and clinical practice, making it subject to limitations of retrospective reports, such as selection bias and incomplete data. Another limitation is the lack of data regarding patient comorbidities and postoperative complications which can be an important confounder contributing to extended in-hospital stay. We observed a high rate of hyponatraemia among patients with rare sellar and parasellar tumours; however, the number of these patients was too small to conclude an association between such tumours and hyponatraemia.

\section{Conclusions}

This study has shown that hyponatraemia, a common complication post transsphenoidal surgery, is associated with prolonged hospital admission and is a common cause of readmission. The limited effectiveness of the current treatment of SIADH highlights the need for prospective studies, evaluating the effectiveness and safety of other therapies for SIADH in this context. Apart from determining the success rate in timely correction of hyponatraemia, these studies should explore the impact of other strategies on outcomes, such as patient's symptomatology, length of hospital stay and readmission rate. In particular, the potential role of tolvaptan, a V2-specific arginine vasopressin receptor antagonist which is the only medication approved by the regulatory authorities in Europe and the USA for the treatment of SIADH, warrants further exploration in these patients.

Supplementary Information The online version contains supplementary material available at https://doi.org/10.1007/s00701-022-05134-9. 
Funding Hani J. Marcus is supported by the Wellcome/EPSRC Centre for Interventional and Surgical Sciences (WEISS) and the NIHR Biomedical Research Centre (BRC) Neuro-oncology.

Data availability The data that support the findings of this study are openly available at https://figshare.com/s/455d5b30d05ab9fd520d.

\section{Declarations}

Ethics approval The study was registered and approved by the local Clinical Governance Committee.

Conflict of interest All authors declare no competing interests.

Open Access This article is licensed under a Creative Commons Attribution 4.0 International License, which permits use, sharing, adaptation, distribution and reproduction in any medium or format, as long as you give appropriate credit to the original author(s) and the source, provide a link to the Creative Commons licence, and indicate if changes were made. The images or other third party material in this article are included in the article's Creative Commons licence, unless indicated otherwise in a credit line to the material. If material is not included in the article's Creative Commons licence and your intended use is not permitted by statutory regulation or exceeds the permitted use, you will need to obtain permission directly from the copyright holder. To view a copy of this licence, visit http://creativecommons.org/licenses/by/4.0/.

\section{References}

1. Agam MS, Wedemeyer MA, Wrobel B, Weiss MH, Carmichael JD, Zada G (2019) Complications associated with microscopic and endoscopic transsphenoidal pituitary surgery: experience of 1153 consecutive cases treated at a single tertiary care pituitary center. J Neurosurg 130(5):1576-1583

2. Barber S, Liebelt B, Baskin D (2014) Incidence, etiology and outcomes of hyponatremia after transsphenoidal surgery: experience with 344 consecutive patients at a single tertiary center. J Clin Med 3(4):1199-1219

3. Bohl MA, Ahmad S, Jahnke H, Shepherd D, Knecht L, White WL, Little AS (2016) Delayed hyponatremia is the most common cause of 30-day unplanned readmission after transsphenoidal surgery for pituitary tumors. Neurosurgery 78(1):84-90

4. Bohl MA, Ahmad S, White WL, Little AS 2018 Implementation of a postoperative outpatient care pathway for delayed hyponatremia following transsphenoidal surgery. Neurosurgery. Oxford University Press, pp 110-117

5. Burke WT, Cote DJ, Sherry -, Iuliano I, Hasan, Zaidi A, Laws ER, (2018) A practical method for prevention of readmission for symptomatic hyponatremia following transsphenoidal surgery. Pituitary 21:25-31

6. Cote DJ, Dasenbrock HH, Muskens IS, Broekman MLD, Zaidi HA, Dunn IF, Smith TR, Laws ER (2017) Readmission and other adverse events after transsphenoidal surgery: prevalence, timing, and predictive factors. J Am Coll Surg 224(5):971-979

7. JF Cusick TC Hagen JW Kindling 2010 Inappropriate secretion of antidiuretic hormone after transsphenoidal surgery for pituitary tumors 101056/NEJM198407053110107311 13638

8. Deaver KE, Catel CP, Lillehei KO, Wierman ME, Kerr JM (2018) Strategies to reduce readmissions for hyponatremia after transsphenoidal surgery for pituitary adenomas. Endocrine 62(2):333-339
9. von Elm E, Altman DG, Egger M, Pocock SJ, Gøtzsche PC, Vandenbroucke JP (2007) The Strengthening the Reporting of Observational Studies in Epidemiology (STROBE) statement: guidelines for reporting observational studies. Lancet 370(9596): 1453-1457

10. Furst H, Md; Hallows KR, Post J, Chen S, Kotzker W, Goldfarb S, Ziyadeh FN, Neilson EG, (2000) The urine/plasma electrolyte ratio: a predictive guide to water restriction. Am J Med Sci Issue 319(4):240-244

11. Garrahy A, Galloway I, Hannon AM, Dineen R, O'Kelly P, Tormey WP, O'Reilly MW, Williams DJ, Sherlock M, Thompson CJ (2020) Fluid restriction therapy for chronic SIAD; results of a prospective randomized controlled trial. J Clin Endocrinol Metab 105(12): $1-10$

12. Gross P (2012) Clinical management of SIADH. Ther Ady Endocrinol Metab 3(2):61-73

13. Guerrero R, Pumar A, Soto A, Pomares MA, Palma S, Mangas MA, Leal A, Villamil F (2007) Early hyponatraemia after pituitary surgery: cerebral salt-wasting syndrome. Eur J Endocrinol 156(6):611-616

14. Hannon MJ, Finucane FM, Sherlock M, Agha A, Thompson CJ (2012) Disorders of water homeostasis in neurosurgical patients. J Clin Endocrinol Metab 97(5):1423-1433

15. Hannon MJ, Thompson CJ 2019 Hyponatremia in neurosurgical patients. Front. Horm. Res. S. Karger AG, pp 143-160

16. Hensen J, Henig A, Fahlbusch R, Meyer M, Boehnert M, Buchfelder M (1999) Prevalence, predictors and patterns of postoperative polyuria and hyponatraemia in the immediate course after transsphenoidal surgery for pituitary adenomas. Clin Endocrinol (Oxf) 50(4):431-439

17. Humayun MA, Cranston IC (2017) In-patient Tolvaptan use in SIADH: care audit, therapy observation and outcome analysis. BMC Endocr Disord. https://doi.org/10.1186/ S12902-017-0214-2

18. Hussain NS, Piper M, Ludlam WG, Ludlam WH, Fuller CJ, Mayberg MR (2013) Delayed postoperative hyponatremia after transsphenoidal surgery: prevalence and associated factors-clinical article. J Neurosurg 119(6):1453-1460

19. Jahangiri A, Wagner J, Tran MT, Miller LM, Tom MW, Kunwar S, Blevins L, Aghi MK (2013) Factors predicting postoperative hyponatremia and efficacy of hyponatremia management strategies after more than 1000 pituitary operations: clinical article. J Neurosurg 119(6):1478-1483

20. Jencks SF, Williams MV, Coleman EA (2009) Rehospitalizations among patients in the Medicare Fee-for-Service Program. N Engl J Med 360(14):1418-1428

21. Kelly DF, Laws ER, Fossett D (1995) Delayed hyponatremia after transsphenoidal surgery for pituitary adenoma. Report of nine cases J Neurosurg 83(2):363-367

22. Kleindienst A, Georgiev S, Schlaffer SM, Buchfelder M (2020) Tolvaptan versus fluid restriction in the treatment of hyponatremia resulting from SIADH following pituitary surgery. J Endocr Soc 4(7):1-14

23. Korzelius CA (2013) CME INFORMATION Diagnosis, evaluation, and treatment of hyponatremia: expert panel recommendations program overview. https://doi.org/10.1016/j.amjmed.2013. 07.006

24. Krogh J, Kistorp CN, Jafar-Mohammadi B, Pal A, Cudlip S, Grossman A (2018) Transsphenoidal surgery for pituitary tumours: frequency and predictors of delayed hyponatraemia and their relationship to early readmission. Eur J Endocrinol 178(3):247-253

25. Morris JH, Bohm NM, Nemecek BD, Crawford R, Kelley D, Bhasin B, Nietert PJ, Carlos J, Velez Q (2018). Rapidity of correction of hyponatremia due to syndrome of inappropriate secretion 
of antidiuretic hormone following tolvaptan. https://doi.org/10. 1053/j.ajkd.2017.12.002

26. O'Connor WJ (1952) The normal interphase in the polyuria which follows section of the supraoptico-hypophysial tracts in the dog. Q J Exp Physiol Cogn Med Sci 37(1):1-10

27. Oh JY, Il SJ (2014) Syndrome of inappropriate antidiuretic hormone secretion and cerebral/renal salt wasting syndrome: similarities and differences. Front Pediatr. https://doi.org/10.3389/FPED. 2014.00146

28. Olson BR, Gumowski J, Rubino D, Oldfield EH (1997) Pathophysiology of hyponatremia after transsphenoidal pituitary surgery. J Neurosurg 87(4):499-507

29. Olson BR, Rubino D, Gumowski J, Oldfield EH (1995) Isolated hyponatremia after transsphenoidal pituitary surgery. J Clin Endocrinol Metab 80(1):85-91

30. Peters JP, Welt LG, Sims EAH, Orloff J, Needham J (1950) A saltwasting syndrome associated with cerebral disease. Trans Assoc Am Physicians 63:57-64

31. Rajaratnam S, Jeyaseelan L, Rajshekhar V (2020) Delayed hyponatremia following surgery for pituitary adenomas: an underrecognized complication. Neurol India 68(2):340

32. Sane T, Rantakari K, Poranen A, Tähtelä R, Välimäki M, Pelkonen R (1994) Hyponatremia after transsphenoidal surgery for pituitary tumors. J Clin Endocrinol Metab 79(5):1395-1398

33. Sata A, Hizuka N, Kawamata T, Hori T, Takano K (2006) Hyponatremia after transsphenoidal surgery for hypothalamopituitary tumors. Neuroendocrinology 83(2):117-122

34. Schrier RW, Gross P, Gheorghiade M, Berl T, Verbalis JG, Czerwiec FS, Orlandi C (2006) Tolvaptan, a selective oral vasopressin V 2 -receptor antagonist, for hyponatremia. N Engl J Med 355(20):2099-2112

35. Spasovski G, Vanholder R, Allolio B et al (2014) Clinical practice guideline on diagnosis and treatment of hyponatraemia. Eur J Endocrinol 170(3):1-47

36. Tomita Y, Kurozumi K, Inagaki K, Kameda M, Ishida J, Yasuhara T, Ichikawa T, Sonoda T, Otsuka F, Date I (2019) Delayed postoperative hyponatremia after endoscopic transsphenoidal surgery for pituitary adenoma. Acta Neurochir (Wien) 161(4):707-715

37. Tzoulis P, Carr H, Bagkeris E, Pierre •, Bouloux M, (2020) Improving care and outcomes of inpatients with syndrome of inappropriate antidiuresis (SIAD): a prospective intervention study of intensive endocrine input vs. routine care. Endocrine 55:539-546

38. Tzoulis P, Waung JA, Bagkeris E, Carr H, Khoo B, Cohen M, Bouloux PM (2016) Real-life experience of tolvaptan use in the treatment of severe hyponatraemia due to syndrome of inappropriate antidiuretic hormone secretion. Clin Endocrinol (Oxf) 84(4):620-626

39. Ultmann MC, Hoffman GE, Nelson PB, Robinson AG (1992) Transient hyponatremia after damage to the neurohypophyseal tracts. Neuroendocrinology 56(6):803-811

40. Verbalis JG, Adler S, Schrier RW, Berl T, Zhao Q, Czerwiec FS (2011) Efficacy and safety of oral tolvaptan therapy in patients with the syndrome of inappropriate antidiuretic hormone secretion. Eur J Endocrinol 164(5):725-732

41. Verbalis JG, Greenberg A, Burst V, Haymann JP, Johannsson G, Peri A, Poch E, Chiodo JA, Dave J (2016) Diagnosing and treating the syndrome of inappropriate antidiuretic hormone secretion. Am J Med 129(5):537.e9-537.e23

42. Winograd D, Staggers KA, Sebastian S, Takashima M, Yoshor D, Samson SL (2020) An effective and practical fluid restriction protocol to decrease the risk of hyponatremia and readmissions after transsphenoidal surgery. Neurosurgery. https://doi.org/10. 1093/neuros/nyz555

43. Yoon HK, Lee HC, Kim YH, Lim YJ, Park HP (2019) Predictive factors for delayed hyponatremia after endoscopic transsphenoidal surgery in patients with nonfunctioning pituitary tumors: a retrospective observational study. World Neurosurg 122:e1457-e1464

44. Younus I, Gerges MM, Dobri GA, Ramakrishna R, Schwartz TH 2019 Readmission after endoscopic transsphenoidal pituitary surgery: analysis of 584 consecutive cases. J Neurosurg 1(aop):1-6

45. Zada G, Liu CY, Fishback D, Singer PA, Weiss MH (2007) Recognition and management of delayed hyponatremia following transsphenoidal pituitary surgery. J Neurosurg 106(1):66-71

Publisher's note Springer Nature remains neutral with regard to jurisdictional claims in published maps and institutional affiliations. 